\title{
Primary CNS Lymphoma: Lymphomatous Meningitis Presenting as a Cauda Equina Lesion in an AIDS Patient
}

\author{
Pavel Klein, Gary Zientek, Scott R. VandenBerg and Eric Lothman
}

\begin{abstract}
Neurologic complications of the acquired immune deficiency syndrome (AIDS) most often present as brain dysfunction and/or a polyneuropathy. We describe a unique neurological problem of a woman with AIDS who presented with a cauda equina mass due to primary CNS lymphoma. She subsequently developed a fulminant lymphomatous meningitis and died. Although previously rare, primary spinal cord lymphoma is expected to be encountered more often with the current AIDS epidemic and may be difficult to distinguish from infectious mass lesions.

RÉSUMÉ: Lymphome primaire du SNC: méningite lymphomateuse se présentant comme une lésion de la queue de cheval chez une patiente atteinte du SIDA Les complications neurologiques du syndrome d'immuno-déficience acquise se présentent le plus souvent comme une dysfonction cérébrale et/ou une polyneuropathic. Nous décrivons un problème neurologique unique chez une femme atteinte du SIDA, qui s'est présentée avec une masse à la queue de cheval due à un lymphome primaire du SNC. Elle a ultérieurement développé une méningite lymphomateuse fulminante et elle est décédée. Même si cette entité était rare dans le passé, il est à prévoir que les lymphomes primaires de la moelle épinière seront plus fréquents à cause de l'épidémie actuelle de SIDA et il peut être difficile de les distinguer des lésions tumorales infectieuses.
\end{abstract}

Can. J. Neurol. Sci. 1990; 17:329-331

Constituting less than $1.5 \%$ of all brain tumors, primary central nervous system (CNS) lymphoma is rare. ${ }^{1}$ Immunosuppression of various causes increases its frequency. ${ }^{1}$ Lymphomas occur in $2 \%$ of patients with the acquired immunodeficiency syndrome (AIDS) ${ }^{2}$ and are being seen with increasing frequency in this context. Primary CNS lymphomas almost always arise intracranially, predominantly in the forebrain, less often in the brainstem. Diffuse meningeal spread (lymphomatous meningitis), noted to occur in $8 / 66(12 \%)$ of presenting patients in a recent series, is usually confined to the cranium. ${ }^{3}$ Meningeal dissemination to the spinal roots from an intracranial focus may sometimes occur at an advanced stage of the disease. ${ }^{4}$ Primary spinal cord involvement by lymphoma, whether of the parenchyma or of the meninges, is rare. No case associated with AIDS has been described. We describe a case of primary CNS lymphoma in an AIDS patient presenting with a spinal mass lesion and lymphomatous meningitis.

\section{CASE REPORT}

A twenty-nine year old white woman with bisexual contacts tested positive for the human immunodeficiency virus (HIV) in 1985. Over the next two and a half years, she twice developed Pneumocystis carinii pneumonia and Herpes simplex dorsal radiculitis. Two years prior to admission she developed symmetrical distal sensory neuropathy of the lower extremities which began in the toes, ascended up to the knees over six months and then arrested at that level.
Two weeks prior to her admission, she awoke with acute low back pain which radiated down the lateral aspect of the left thigh and calf, was exacerbated by cough, and was associated with numbness. The nexi day, the left leg became weak. Over the next two weeks the pain worsened, she lost all use of her left leg and developed urinary hesitancy, without urgency or incontinence.

Physical examination revealed a cachectic, afebrile woman. Respiratory, cardiovascular and abdominal examination was normal. There was no Kernig's or Brudzinski's sign. Abnormal findings consisted of flaccid $1 / 5$ weakness of all muscles of the left lower extremity. bilateral distal lower extremity sensory impairment up to knee level, and diffuse hyperreflexia, except for areflexia in the left leg. Right plantar response was flexor; there was no plantar response on the left.

Laboratory investigations included normal serum electrolytes and liver function tests, white cell count of 2.9 (83\% neutrophils, $9 \% \mathrm{lym}$ phocytes) and hematocrit of 31.8 . Serum cryptococcal antigen was negative. CSF studies showed protein of $188 \mathrm{mg} / \mathrm{dl}$, glucose of $13 \mathrm{mg} / \mathrm{dl}$ (serum glucose 94 ) and 20 white cells with $75 \%$ neutrophils, $15 \%$ monocytes and $9 \%$ lymphocytes. A few atypical lymphocytes were seen, but cytological examination was negative for malignant cells. Mycobacterium avium intracellulare bacilli were isolated from CSF culture. Other bacterial, viral and fungal studies were negative. Magnetic resonance imaging (MRI) scan of the spinal cord showed an expansive lesion in the cauda equina at $\mathrm{Ll}$ level and a thickening of the nerve roots at Ll-2 level, more prominent on the left (Figure 1). Computerized tomographic (CT) myelography demonstrated a large intradural mass at the same level, with thickening and nodularity of multiple nerve roots inferior to the $\mathrm{Ll}$ level. CT scan of the head showed no focal lesions. The patient was not on steroids at the time.

From the Departments of Neurology (P.K., E.L.) and Pathology (G.Z., S.R.V.), University of Virginia Medical Center, Charlottesville, Virginia Received October 24, 1989. Accepted in final form January 21, 1990

Reprint requests to: Pavel Klein, M.B., B.Ch. Department of Neurology, Box 394, University of Virginia Medical Center, Charlottesville, Virginia 22908 U.S.A. 
L1-2 laminectomy revealed macroscopic encasement of the nerve roots by a friable, partly necrotic tumor. Microscopic examination disclosed diffuse infiltration of the nerve roots by a large cell lymphoma. The heterogeneous tumor cells were often large with variably abundant cytoplasm, pleomorphic nuclei and frequently prominent nucleoli. Mitotic figures were frequent. Deparaffinised tissue showed diffuse weak immunoreactivity of the malignant cells for commun leukocyte antigen and strong reactivity for B-lymphocyte markers (L26 and LN2) with no detectable immunoglobulin light chain.

In the course of the next 4 weeks she developed right IInd and VIth, bilateral VIIIth, left peripheral VIIth, IXth and Xth nerve palsies, right lower extremity flaccid plegia, and loss of both urinary and anal sphincter functions. CT scan of the head repeated one day prior to death showed contrast enhancement of a mildly enlarged $(4 \mathrm{~mm})$ septum pellucidum. The patient expired five weeks after her initial neurological presentation.

\section{Postmortem Studies}

No lymphoma was present outside of the nervous system. A diffuse abdominal Mycobacterium avium intracellulare infection and bilateral Candida albicans pneumonia were present. A plaque-like, partially necrotic tumor mass was infiltrating the upper lumbar spinal cord posteriorly. Adjacent, partially necrotic nerve roots were encased in and infiltrated by the tumor (Figure 2). Microscopic and immunohistochemical examination showed features similar to those found in the surgical biopsy. Within the brain, multiple necrotic tumor masses $\mathbf{0 . 0 3 -}$ $0.06 \mathrm{~cm}^{3}$ ) were attached to the ventricular surface of a thickened septum pellucidum. In the basal ganglia, thalamus and corpus

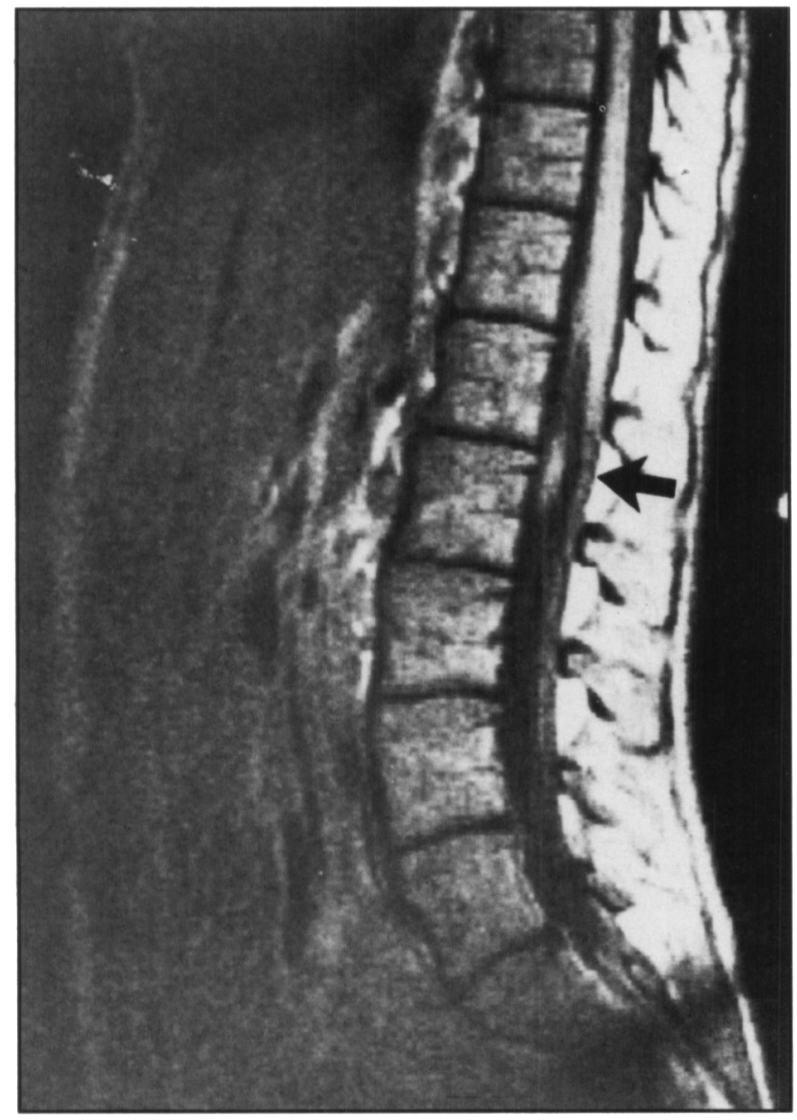

Figure I - TI weighted sagittal sequence magnetic resonance image of thoracolumbar spine showing an oval area of high signal density representing a mass within the cauda equina anteriorly (arrow).

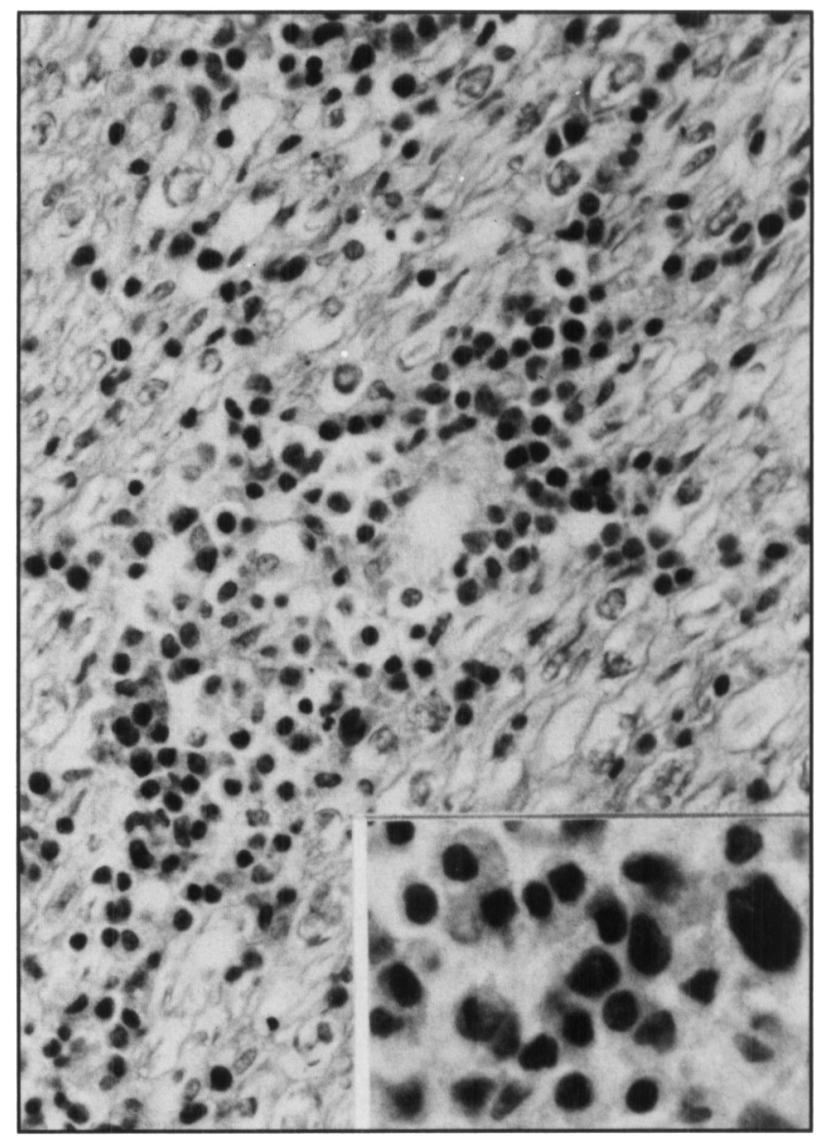

Figure 2 - Section of nerve roots at $\mathrm{Ll}$ level showing infiltration of the root by lymphoma cells (hemotoxylin and eosin stain. $X 300)$. Inset: The tumor infiltrates are pleomorphic and contain large cells with hyperchromatic, irregular nuclei (hemotoxylin and eosin stain, X600)

callosum, there was variable angiocentric parenchymal infiltration by tumor cells. There was a dense, diffuse lymphomatous leptomeningitis throughout the neural axis.

\section{Discussion}

In systemic lymphoma, diffuse meningeal spread (lymphomatous meningitis) occurs commonly and frequently affects the spinal cord and roots. By contrast, in a recent large series only $8 / 66(12 \%)$ of patients with primary CNS lymphoma had meningeal dissemination at the initial presentation, ${ }^{3}$ usually confined to the cranium. Spinal cord and roots are rarely involved in primary CNS lymphoma. Only nine such cases have previously been described, six with intradural spinal cord lesions ${ }^{5-10}$ and three with involvement of spinal roots and the meninges. ${ }^{11-13}$ The present case is the tenth and first such case to be described in an AIDS patient.

As many as one in fifty of the individuals with AIDS will develop primary CNS lymphoma. ${ }^{2}$ Thus, in conjunction with the current AIDS epidemic, it is expected that clinical situations like the one described here will be met with increasing frequency.

The differential diagnosis of an intraspinal mass in an immunocompromised patient includes infectious lesions, such as tuberculous or cryptococcal granulomata, toxoplasmosis or pyogenic abscess eroding from the epidural space intradurally. 
In addition, neoplasms which may affect the immunocompromised patient include systemic malignancy (carcinoma, lymphoma) or primary intramedullary or extramedullary tumors. The present case suggests that primary CNS lymphoma needs to be added this differential diagnosis.

Initial diagnostic strategy revolves around examination of the CSF and neuroimaging, but these may prove problematic. In the current case, MR imaging demonstrated the anatomical lesion. The CT confirmed the defect and documented its intradural location. In review, we believe that MRI is the procedure of choice for the diagnosis under discussion and makes myelography, with or without CT studies, unnecessary. Difficulty was encountered in interpreting the CSF findings. Abnormalities of the cell count and protein and glucose levels similar to those cited above have been reported in up to half of AIDS patients with primary CNS lymphoma. ${ }^{15}$ Nonetheless, the findings were nonspecific, consistent with infection as well. Specialized CSF studies (cytology and immunoperoxidase staining) did not distinguish tumor from infection. However, surgical biopsy led to the diagnosis. Radiotherapy is recommended for CNS lymphoma, both in patients with and without AIDS.14-15 In the latter instance, radiation may prolong life. ${ }^{14}$ Even if not, it is likely to provide palliation for pain, particularly in patients with spinal cord and/or nerve root lesions. In this context, diagnosis is of the utmost importance. Relying on the results of lumbar punctures spaced days apart could well retard or perhaps even prevent initiation of effective treatment.

\section{REFERENCES}

1. Jellinger K, Radaskiewicz TH, Slowik F. Primary malignant lymphomas of the central nervous system in man. Acta Neuropathol [Suppl] (Berl) 1975; 6: 95-102.
2. Rosenblum, ML, Levy RM, Bredesen DE, et al. Primary central nervous system lymphomas in patients with AIDS. Ann Neurol 1988; 23 (Suppl): 13-16.

3. Hochberg FH, Miller DC. Primary central nervous system lymphoma. J Neurosurg 1988; 68: 835-853.

4. Case Records of the Massachusetts General Hospital (Case $33-$ 1988). N Engl J Med 1988; 319: 426-436.

5. Reznik M. Pathology of primary reticulum cell sarcoma of the human central nervous system. Acta Neuropathol [Suppl] (Berl) 1975; 6: 91-94.

6. Herbst KD, Corder MP, Justice GR. Successful therapy with methotrexate of a multicentric mixed lymphoma of the central nervous system. Cancer 1976; 38: 1476-1478.

7. Bruni J, Bilbao JM, Gray T. Primary intramedullary malignant lymphoma of the spinal cord. Neurology 1977; 27: 896-898.

8. Mitsumoto H, Breuer AC, Lederman RJ. Malignant lymphoma of the central nervous system: a case of primary spinal intramedullary involvement. Cancer 1980; 46: 1258-1262.

9. Slager UT, Kaufman RL, Cohen K, et al. Primary lymphoma of the spinal cord. J Neuropathol Exp Neurol 1982; 41: 437-445.

10. Hautzer NW, Aiyesimoju A, Robitaille Y. "Primary" spinal intramedullary lymphumas: a review. Ann Neurol 1983; 14: 62-66.

11. Case Records of the Massachusetts General Hospital (Case 12 1985). N Engl J Med 1985; 312: 774-783.

12. Mauncy M, Sciotto CG. Primary malignant lymphoma of the cauda equina. Am J Surg Pathol 1983; 7: 185-190.

13. Buchholz DW, White CL, Bergey GK, et al. Relapsing and remitting neuropathy caused by "occult" lymphoma of the peripheral nervous system. J Neuropathol Exp Neurol 1984; 43: 354.

14. Murray K, Kun L, Cox J. Primary malignant lymphoma of the central nervous system. Results of treatment of 11 cases and review of the literature. J Neurosurg 1986; 65: 600-607.

15. So YT, Beckstead JH, Davis RL. Primary central nervous lymphoma in acquired immune deficiency syndrome: a clinical and pathological study. Ann Neurol 1986; 20: 566-572. 